"This accepted author manuscript is copyrighted and published by Elsevier. It is posted here by agreement between Elsevier and MTA. The definitive version of the text was subsequently published in INTERNATIONAL JOURNAL OF BIOLOGICAL MACROMOLECULES 72: 1034-1040 (2015) doi:10.1016/j.ijbiomac.2014.10.009." 


\title{
Apparent circular dichroism signature of stirring-oriented DNA and drug-DNA complexes
}

\author{
Ferenc Zsila* \\ Chemical Biology Research Group, Institute of Organic Chemistry, \\ Research Centre for Natural Sciences, Hungarian Academy of Sciences, POB 289, \\ H-1519, Budapest, Hungary
}

Corresponding author: Ferenc Zsila

POB 289, H-1519, Budapest, Hungary

Fax: (+36) 1-438-1145

Email: zsila.ferenc@ttk.mta.hu 


\begin{abstract}
It is shown that in water with no added salts calf-thymus DNA and its drug-loaded forms exhibit peculiar, completely reversible circular dichroism (CD) spectroscopic changes upon mechanical rotatory stirring. Due to the stirring-induced spatial alignment of the helices, the CD spectra are overwhelmed by the much more intense linear dichroism contribution. This apparent chiroptical response can be generated and detected by an ordinary CD spectropolarimeter without using any sophisticated attachment. It is a technically simple complement to existing methods suitable to obtain additional structural information which can not be derived from isotropic spectra. DrugDNA interactions generating no or very weak CD spectroscopic changes under isotropic conditions become easily detectable upon stirring the sample solution. Stirring-induced changes of the ellipticity profile also enable to clarify the DNA binding mode of various compounds (e.g., imatinib, thioflavin T) which would remain ambiguous considering isotropic spectral data only.
\end{abstract}

Keywords: alkaloids; DNA; groove binding; imatinib; intercalation; linear dichroism; oriented circular dichroism; stirring, thioflavin $\mathrm{T}$

Abbreviations: bp, base pair; CD, circular dichroism; LD, linear dichroism; rpm, revolutions per minute 


\section{Introduction}

Hydrodynamic forces can be used to orient long, flexible, rod-like macromolecules in solution

[1]. In relation to the isotropic environment, flow orientation deeply alters the optical properties of biopolymers. Analysis of circular (CD) and linear dichroism (LD) spectra of flow-oriented DNA molecules enables to derive structural information both on their native and drug bound forms [2-4]. The flow field is usually generated by special devices such as Couette cell [5] or by pumping through capillaries [4] or narrow gaps. The present contribution demonstrates how widely used commercial CD spectropolarimeter can be utilized for generation of flow-oriented DNA samples. Using no sophisticated accessories, this simple, cost-free approach can widely be employed to extend the capability of CD equipments to gain additional structural information on drug-DNA binding interactions. 


\section{Experimental}

\subsection{Materials}

Calf thymus DNA sodium salt was purchased from Calbiochem (cat No. 2618, Lot B37065, $42 \% \mathrm{G}+\mathrm{C}$, highly polymerized, mean molecular mass is about $2 \times 10^{7} \mathrm{Da}$ ). Proflavine hemisulfate dihydrate (Sigma), thioflavin T (Calbiochem), Hoechst 33342 (Sigma), DAPI diHCl (Fluka), quinacrine diHCl (Sigma), quinaldine red (Sigma), ethidium bromide (Sigma), daunorubicin $\mathrm{HCl}$ (Sigma), imatinib mesylate (LC Lab), berberine $\mathrm{HCl}$ (Sigma), sanguinarine chloride (Sigma), harmine (Sigma), norharmane $\mathrm{HCl}$ (Sigma), and ellipticine (Calbiochem) were used as supplied.

\subsection{Preparation of DNA and ligand solutions}

DNA stock solutions were prepared at $2-4 \mathrm{mg} / \mathrm{mL}$ in ultra-pure water $(18.2 \mathrm{~m} \Omega)$ and kept overnight at $4{ }^{\circ} \mathrm{C}$. The stock solutions were then aliquoted and stored at $-20{ }^{\circ} \mathrm{C}$. DNA concentration in term of base pair/L was determined spectrophotometrically by using a molar extinction coefficient of $\varepsilon_{\max }=13,200 \mathrm{M}^{-1} \mathrm{~cm}^{-1}$ at $260 \mathrm{~nm}$. DNA ligands were also dissolved in ultrapure water.

The $\mathrm{pH}$ value of working DNA solution $(0.05 \mathrm{mg} / \mathrm{mL})$ was 6.68 , as measured using a benchtop Mettler Toledo SevenEasy pH meter (model S20).

\subsection{CD and UV absorption spectroscopic measurements}

CD and UV absorption spectra were recorded on a JASCO J-715 spectropolarimeter at $25 \pm$ $0.2{ }^{\circ} \mathrm{C}$. Temperature control was provided by a Peltier thermostat equipped with magnetic stirring (JASCO PFD-350S). A teflon-coated magnetic star head stirring bar $(\varnothing 10 \mathrm{~mm} \times 8$ $\mathrm{mm}$, Nalgene cat. no. 6600-0010) was placed at the bottom of a rectangular quartz cell of 1 
cm optical pathlength (Hellma, USA) which then was filled with $1.8 \mathrm{~mL}$ ultrapure water. CD and HT curves were recorded as a blank for correction of DNA and drug-DNA spectra. After thawing the frozen stock solution of DNA, a small aliquot from it $(30-50 \mu \mathrm{L})$ was manually pipetted into $1.8 \mathrm{~mL}$ stirred or non-stirred water and then spectral scanning was performed. Stirred and non-stirred DNA solutions were titrated with $\mu \mathrm{L}$ aliquots of ligand stock solutions. Each spectrum represents the average of three scans obtained by collecting data at a scan speed of $100 \mathrm{~nm} / \mathrm{min}$. JASCO CD spectropolarimeters record CD data as ellipticity (' $\theta$ ) in units of millidegrees (mdeg).

Absorption spectra were obtained by conversion of the high voltage (HT) values of the photomultiplier tube of the CD equipment into absorbance units. 


\section{Results and discussion}

The JASCO Peltier temperature control module equipped to $\mathrm{CD}$ machines contains an integrated, variable speed magnetic stirrer (Supplementary Fig. 1A, 1B). Rotation of the star head stirring bar at the bottom of a $1 \mathrm{~cm}$ pathlength quartz cuvette does not affect the CD spectrum of calf-thymus DNA dissolved in buffer solution (data not shown). However, DNA solution prepared by using distilled water with no added salts behaves quite differently. When the stirrer does not operate, the CD spectrum displays the well-known, conservative ellipticity pattern characteristic to the B-form of DNA [6] indicating that the molecules orient randomly in space (see Supporting Information for experimental details). Upon stirring, however, the CD curve changes dramatically showing a large deviation in relation to the isotropic spectrum. The positive bands above $200 \mathrm{~nm}$ completely vanish and are replaced by two intense negative peaks centered around 205 and $260 \mathrm{~nm}$ (Fig. 1A). This spectral transformation is completely reversible: the original, conservative CD spectrum can promptly be restored by stopping the stirrer and after the stirring is resumed the noted spectral modifications can be observed again (data not shown). In contrast to the CD profile, the UV absorption spectrum remains invariant either under 'stirring' or 'non-stirring' conditions (Fig. 1A).

The magnitudes of these apparent CD signals are proportional to the rotational speed showing a maximum at $600 \mathrm{rpm}$ (Supplementary Fig. 2). At higher rotation rates, peak intensities exhibit some reduction presumably due to the increasing turbulence of the solution that limits spatial ordering of the DNA helices. Furthermore, the stirring-induced spectrum shows substantial temperature dependence: magnitudes of the bands strongly increase upon cooling reaching a four-fold intensity enhancement at $3{ }^{\circ} \mathrm{C}$ (Supplementary Fig. 3). It refers to that only a smaller fraction of the DNA molecules are oriented at $25^{\circ} \mathrm{C}$. In contrast, heating of the 
solution produces an opposite effect decreasing the magnitude of the CD peaks and finally restoring the conservative spectrum around $40{ }^{\circ} \mathrm{C}$ (Supplementary Fig. 3). Analogous phenomenon can be observed upon successive addition of mono- and divalent cations into the solution. Despite continuous stirring, increasing concentrations of $\mathrm{Na}^{+}, \mathrm{Mg}^{2+}, \mathrm{Zn}^{2+}$, and $\mathrm{Cu}^{2+}$ ions gradually convert the CD spectrum back into its conservative form (Supplementary Fig. 4).

These findings imply that the hydrodynamic flow generated by the stirring orients the DNA molecules resulting optical anisotropy. The very low ionic strength is essential for the generation of this state since higher concentration of cationic species increases the flexibility of DNA helices and thereby hinders their spatial ordering [7]. The hydrodynamic flow field induced by rotation of the stirring bar is sufficient to orient the DNA molecules since the Coulombic repulsion between the unshielded, negatively charged phosphate groups enhances the rigidity of the polynucleotide chains. Addition of counterions renders the double helices more flexible so the flow gradient becomes insufficient to orient the DNA molecules and thus the anisotropic CD pattern vanishes. It is to be noted that in special devices suitable to generate much higher hydrodynamic flow gradient (e.g., Couette flow cell), the DNA helices can be aligned even in the presence of salts and display very similar spectral pattern to that reported here $[3,8,9]$.

Raising the temperature also cancels the spatial ordering by decreasing the viscosity of the solution and enhancing Brownian motion of the polynucleotide chains. Vice versa, cooling of the sample greatly facilitates the orientation of the DNA molecules.

It is well known that spatial orientation of light absorbing molecules generates linear dichroism $\left(L D=A_{\|}-A_{\perp}\right)[2,3]$. Since $L D$ signals tend to be orders of magnitude larger than the $\mathrm{CD}$ ones, it can be supposed that the $\mathrm{LD}$ effect makes a chief contribution to the CD spectrum of stirred solutions [10,11]. Prevalence of the LD contribution is supported by close 
resemblance of the anomalous CD curves presented in this work (see further spectra below) to the flow LD spectra of DNA [5] and drug-DNA complexes [8,12] recorded in Couette flow cells suggesting similar orientation of DNA molecules in both cases. As it follows from the definition of $\mathrm{LD}$, positive LD spectrum can be obtained by changing the flow orientation. In the present case, this can be achieved by placing the stir bar in another orientation where its rotation generates a hydrodynamic flow perpendicular to the former one (Supplementary Fig. 1C). The DNA molecules are now aligned along the long axis of the cuvette, so they exhibit an inverted, positive LD effect (Fig. 1B). The observed spectrum is dominated again by the LD signals but, similarly to the horizontally oriented axis, it must contain a masked isotropic CD contribution of the unoriented DNA fraction which can be resolved by a simple procedure. Arithmetic sum of the spectra measured under distinct flow orientations of DNA helices cancels the opposite LD signals resulting a curve which is very similar to the isotropic, conservative CD pattern of DNA (Fig. 1B).

The above considerations can be applied for interpretation of stirring-induced spectral alterations of ligand-DNA complexes, too. Neutral and cationic ligand molecules having an aromatic framework can be inserted between DNA base pairs [2]. According to this binding mode, the guest molecules are incorporated into the stacked chromophoric system of DNA and thus exhibit analogous spectroscopic changes upon spatial alignment. Therefore, a negative LD contribution allied to the respective absorption bands of the intercalated ligand molecules can be expected. In full concordance with this, typical DNA intercalators such as proflavine [13], ethidium bromide [13], and ellipticine [14] display negative LD bands in stirring-oriented DNA sample (Fig. 2) indicating that the $\pi-\pi^{*}$ transition moments of the bound species are oriented perpendicular to the helix axis. Since magnitude of the LD signal is much higher than that of the $\mathrm{CD}$, intercalation can be more sensitively detected in stirringoriented samples than in isotropic solution. As it is illustrated in the case of berberine [15], 
harmine [16] and quinacrine [17], at low drug/bp ratios DNA association of these molecules induces no detectable CD activity in isotropic solution (Fig. 3). The stirred samples, however, exhibit well-resolved negative bands between 300 and $400 \mathrm{~nm}$, the amplitudes of which increase proportionally with the concentration of the ligands. Analogous phenomena were observed by using other DNA intercalating agents including sanguinarine [18], norharmane [19], and isocryptolepine [20] (data not shown).

Isotropic titration of DNA with thioflavin T results in a weak, noisy, negative CD band allied to the respective absorption band of the dye (Fig. 4). In stark contrast to this, a much more intense negative peak can be measured in the CD spectrum of the stirred sample indicating the intercalative binding mode of thioflavin $\mathrm{T}$ (Fig. 4). Interestingly, above 0.13 dye/bp ratio an additional positive $\mathrm{CD}$ band develops around $418 \mathrm{~nm}$ (not shown) suggesting the heterogeneity of the binding at higher ligand concentrations. It is to be noted that the aromatic framework of thioflavin T resembles to that of DAPI, the widely used fluorescent DNA probe. Depending on the nature of the nucleotide sequences, DAPI can interact with DNA either by intercalation or groove binding geometry [2,21].

The cationic dye quinaldine red is a nucleic acid-binding agent, the DNA interaction of which provokes a remarkable enhancement in its fluorescence emission [22]. Although the large red shift of the absorption band of the dye indicates its DNA association, no induced CD signals can be observed in isotropic solution (Fig. 5). Upon stirring of the sample, however, a negative apparent $\mathrm{CD}$ band is displayed suggesting the intercalation of quinaldine red. Similarly to the DNA binding of methylene blue [7], accomodation of the dye molecules within the intercalation pocket may occur in two different orientations in relation to the base pairs giving rise to both positive and negative CD contribution, respectively. Presumably due to the small energy difference, these binding dispositions of quinaldine red are approximately equally populated so their opposite CD contributions mutually cancel each other under 
isotropic condition (rpm 0). However, the sign of the LD depends only on the relative orientation of the plane of intercalated molecules to the long axis of the helix. Since it is perpendicular in both instances, negative LD contribution will be dominant producing a negative apparent ellipticity band (rpm 600). Overall, while the isotropic CD spectrum is inconclusive for recognition the intercalation of quinaldine red, the stirring-induced apparent CD profile refers to this binding mode.

Stirring-induced orientation provides another possibility for detection of drug-DNA associates. Intercalation of rigid, planar aromatic compounds affects the conformation of the polynucleotide chain: the double helix unwinds, stiffens, and lengthens in the region of the intercalated ligands resulting the intensification of the $\mathrm{CD}$ signals allied to the base pairs due to the more effective alignment of the drug-loaded helices [17,23]. More than two-fold ellipticity increase was observed upon intercalation of daunorubicin (not shown), proflavine, $\beta$-carboline and benzylisoquinoline alkaloids (Supplementary Fig. 5). In relation to these large intensity changes, the intrinsic CD bands of DNA measured in isotropic solution showed much more limited alterations upon addition of the same ligand molecules (Supplementary Fig. 6).

In isotropic solution, DNA binding of the anticancer agent imatinib induces a broad, negative CD band centered around $314 \mathrm{~nm}$ (Fig. 6). Concomittantly, magnitude of the intrinsic positive CD peak of DNA is greatly depressed while the ellipticity pattern below $263 \mathrm{~nm}$ remains unaffected. The absorption curve of imatinib measured in the presence of DNA strongly deviates from that obtained in DNA-free solution showing a red shift, hypochromism, and resolved band structure (Fig. 6). Such spectral alterations might be indicative to the intercalation of imatinib but due to the large conformational flexibility of the molecule this presumption is rather dubious (i.e., upon DNA binding imatinib can adopt a conformation in which the $\pi-\pi$ conjugation between its aromatic rings significantly decreases leading to UV 
hypochromism). However, two-fold increase of the anisotropic CD bands of stirring-oriented DNA observed upon addition of imatinib (Fig. 6) helps to clarify this issue providing supportive evidence for the intercalation geometry ( $c f$., Supplementary Fig. 5).

In contrast to the intercalative agents, long-axis polarized transition moment of typical DNA minor groove binders is oriented at approximately $45^{\circ}$ to the helix axis. Thus, DNA-bound form of such compounds gives rise to positive induced CD and LD signals under both isotropic and stirring-oriented condition [2]. In accord with this, the minor groove binder DAPI and Hoechst 33342 exhibit positive induced CD band in stirred and non-stirred solutions (Supplementary Fig. 7 and 8). Shape and position of the bands are similar to those of isotropic samples, but they show a higher intensity presumably due to the orientation effect.

It is worth to note that similarly to the intrinsic CD bands of DNA, stirring-induced apparent CD bands of DNA associated compounds can be converted back to the isotropic signals upon raising the temperature or addition of inorganic salts (data not shown).

Stirring of DNA-free aqueous solution of ligand molecules does not induce either CD or absorption spectroscopic changes (Supplementary Fig. 9A-D).

In conclusion, this work demonstrates a novel, simple method for generation and investigation of oriented DNA samples utilizing a widely available conventional CD spectropolarimeter equipped with a Peltier temperature controller. As it can be inferred from the experiments, stirring of DNA solution prepared in distilled water orients the helices of which strong LD contribution results in apparent $\mathrm{CD}$ activity. Ligand molecules bound to the polynucleotide chains are also aligned and thus exhibit intense, negative or positive anisotropic CD bands depending on their intercalative or groove binding topology. In several cases, when the insertion of aromatic compounds between the base pairs remains undetectable by conventional, isotropic CD measurements, investigation of the stirred samples discloses the 
formation of ligand-DNA complexes. An additional advantage of the stirring-induced orientation technique versus the conventional $\mathrm{CD}$ approach is its higher sensitivity to conformational alteration of the double helix which can also be exploited to detect drug-DNA interactions and to clarify the binding mode of DNA ligands. 


\section{Supplementary data}

Supplementary data associated with this article can be found, in the online version, at http://dx.doi.org/xxxxxxxxxx.

\section{Acknowledgement}

The author grateful to Celesztina Domonkos for her technical assistance. Financial support of the 'Lendület' Program of the Hungarian Academy of Sciences (LP2013-55/2013) is acknowledged. 


\section{References}

[1] A. Rodger, R. Marrington, M.A. Geeves, M. Hicks, L. de Alwis, D.J. Halsall, T.R. Dafforn, Phys. Chem. Chem. Phys. 8 (2006) 3161-3171.

[2] M. Eriksson, B. Nordén, Methods Enzymol. 340 (2001) 68-98.

[3] M.R. Hicks, J. Kowalski, A. Rodger, Chem. Soc. Rev. 39 (2010) 3380-3393.

[4] S.Y. Chung, G. Holzwarth, J. Mol. Biol. 92 (1975) 449-466.

[5] R. Marrington, T.R. Dafforn, D.J. Halsall, J.I. MacDonald, M. Hicks, A. Rodger, Analyst 130 (2005) 1608-1616.

[6] J. Kypr, I. Kejnovska, D. Renciuk, M. Vorlickova, Nucleic Acids Res. 37 (2009) 1713-1725.

[7] B. Nordén, F. Tjerneld, Biopolymers 21 (1982) 1713-1734.

[8] G. Behravan, M. Leijon, U. Sehlstedt, B. Nordén, H. Vallberg, J. Bergman, A. Graslund, Biopolymers 34 (1994) 599-609.

[9] D.S. Pilch, C. Yu, D. Makhey, E.J. LaVoie, A.R. Srinivasan, W.K. Olson, R.R. Sauers, K.J. Breslauer, N.E. Geacintov, L.F. Liu, Biochemistry 36 (1997) 12542-12553.

[10] A. Davidsson, B. Nordén, S. Seth, Chem. Phys. Lett. 70 (1980) 313-316.

[11] F. Tardani, P. Strobbia, A. Scipioni, C. La Mesa, RSC Adv. 3 (2013) 25917-25923.

[12] H.K. Kim, J.M. Kim, S.K. Kim, A. Rodger, B. Norden, Biochemistry 35 (1996) 1187-1194. 
[13] C. Bailly, J.P. Henichart, P. Colson, C. Houssier, J. Mol. Recognit. 5 (1992) 155171.

[14] A. Canals, M. Purciolas, J. Aymami, M. Coll, Acta Crystallogr. D 61 (2005) 10091012.

[15] M. Maiti, G.S. Kumar, Med. Res. Rev. 27 (2007) 649-695.

[16] S. Nafisi, M. Bonsaii, P. Maali, M.A. Khalilzadeh, F. Manouchehri, J. Photochem. Photobiol. B 100 (2010) 84-91.

[17] S.M. Doglia, B. Albinsson, C. Hiort, B. Nordén, A. Gräslund, Biopolymers 33 (1993) 1431-1442.

[18] M. Hossain, G.S. Kumar, J. Chem. Thermodynamics 41 (2009) 764-774.

[19] K. Hayashi, M. Nagao, T. Sugimura, Nucleic Acids Res. 4 (1977) 3679-3685.

[20] S. Van Miert, S. Hostyn, B.U. Maes, K. Cimanga, R. Brun, M. Kaiser, P. Matyus, R. Dommisse, G. Lemiere, A. Vlietinck, L. Pieters, J. Nat. Prod. 68 (2005) 674-677.

[21] A. Biancardi, T. Biver, F. Secco, B. Mennucci, Phys. Chem. Chem. Phys. 15 (2013) 4596-4603.

[22] W.Y. Li, K. Miao, H.L. Wu, X.W. He, H. Liang, Microchim. Acta 143 (2003) 3337.

[23] S.K. Kim, J.-S. Sun, T. Garestier, C. Hélène, C.H. Nguyen, E. Bisagni, A. Rodger, B. Nordén, Biopolymers 42 (1997) 101-111. 

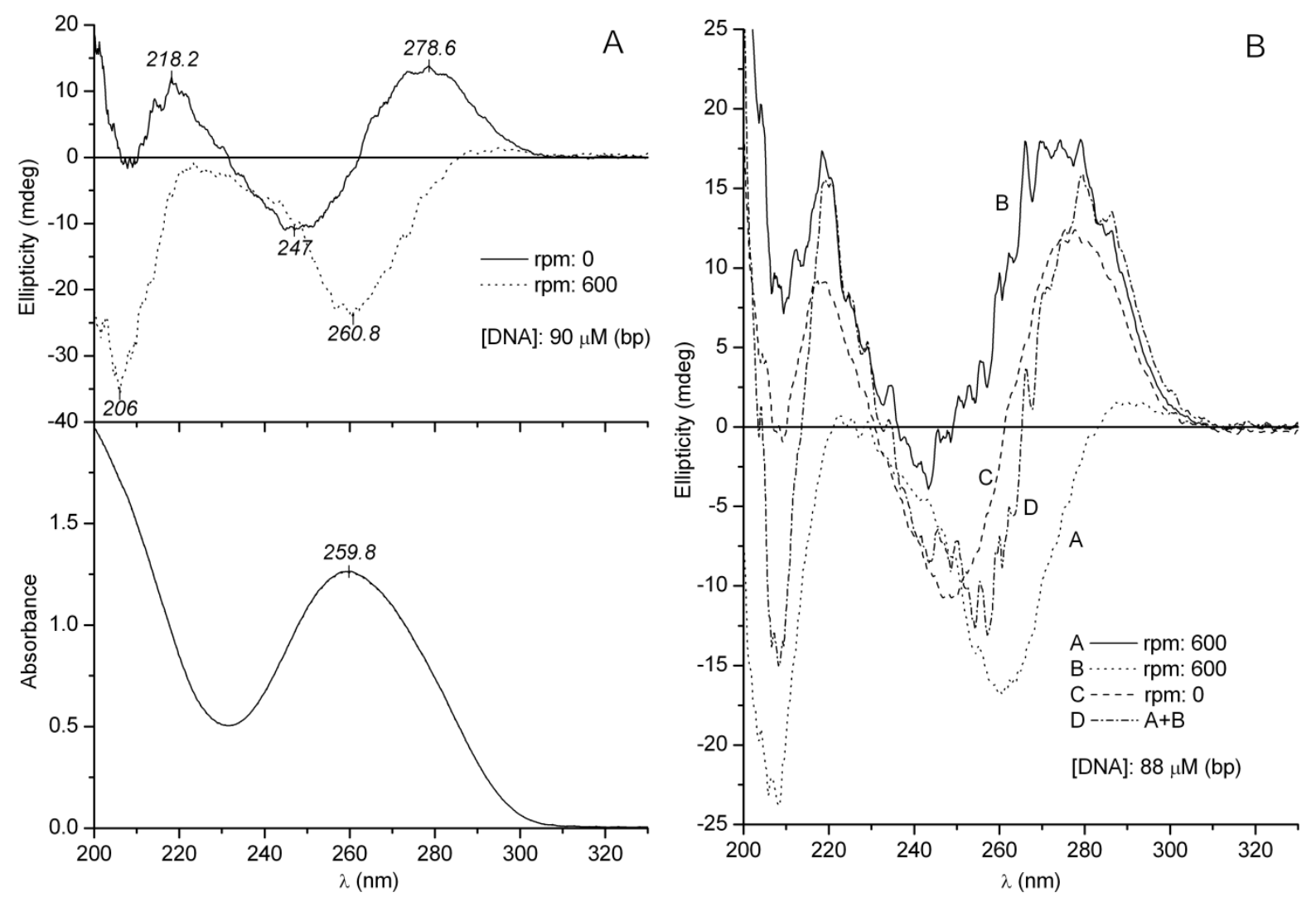

\section{Figure 1A}

CD and UV absorption spectrum of calf-tymus DNA under stationary and under stirring condition in aqueous solution at $\mathrm{pH} 6.7\left(25^{\circ} \mathrm{C}\right)$.

\section{Figure 1B}

CD spectra of DNA measured in isotropic (rpm: 0, curve ' $\mathrm{C}$ ') and in stirred solution. Curve ' $\mathrm{A}$ ' and ' $\mathrm{B}$ ' refer to the position ' 1 ' and ' 2 ' of the star head stirring bar as shown in Suppl. Fig. 1C. 


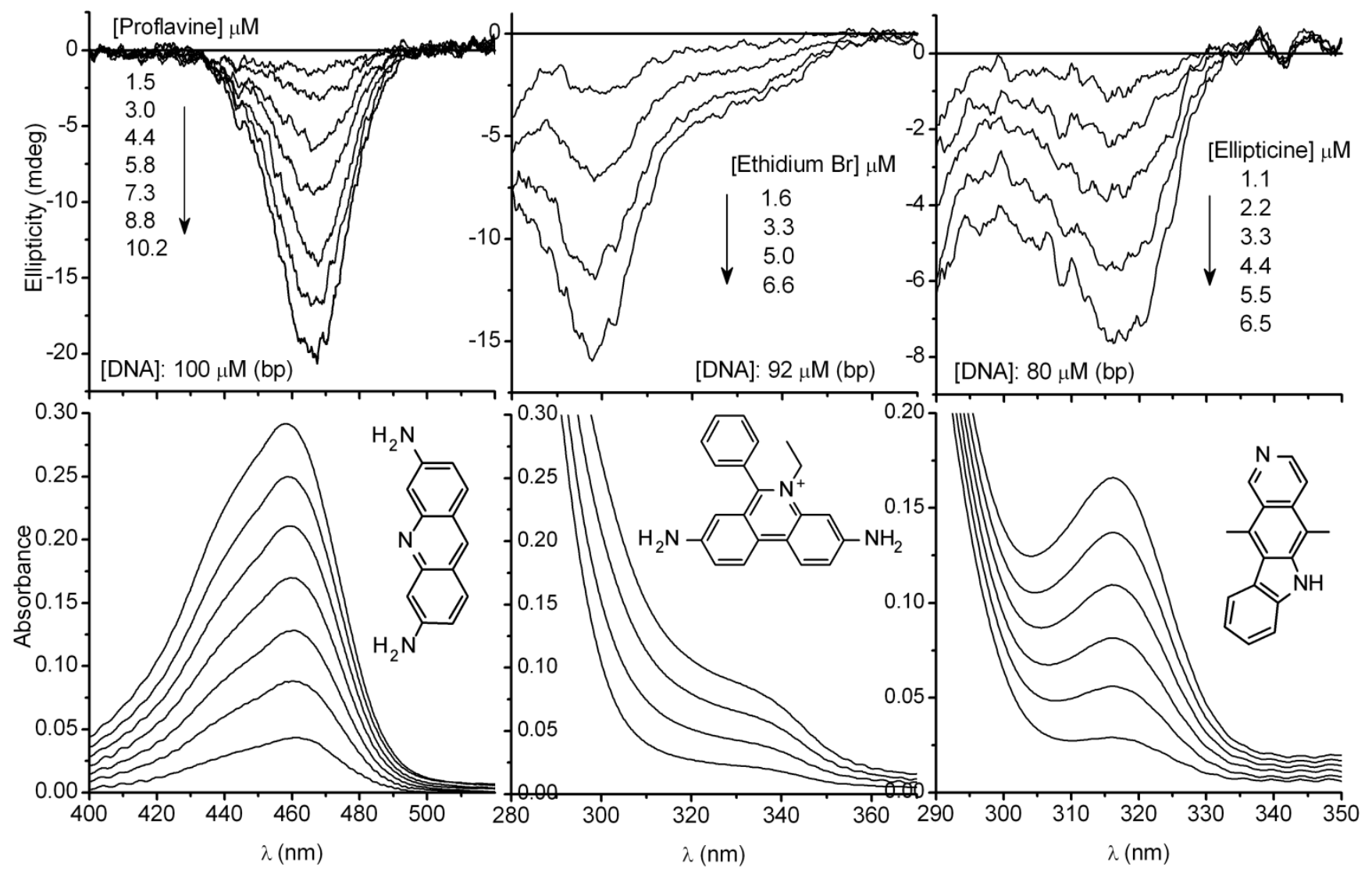

Figure 2

$\mathrm{CD}$ and absorption spectra of stirring-oriented drug-DNA complexes $\left(25^{\circ} \mathrm{C}, \mathrm{rpm}: 600\right)$. 


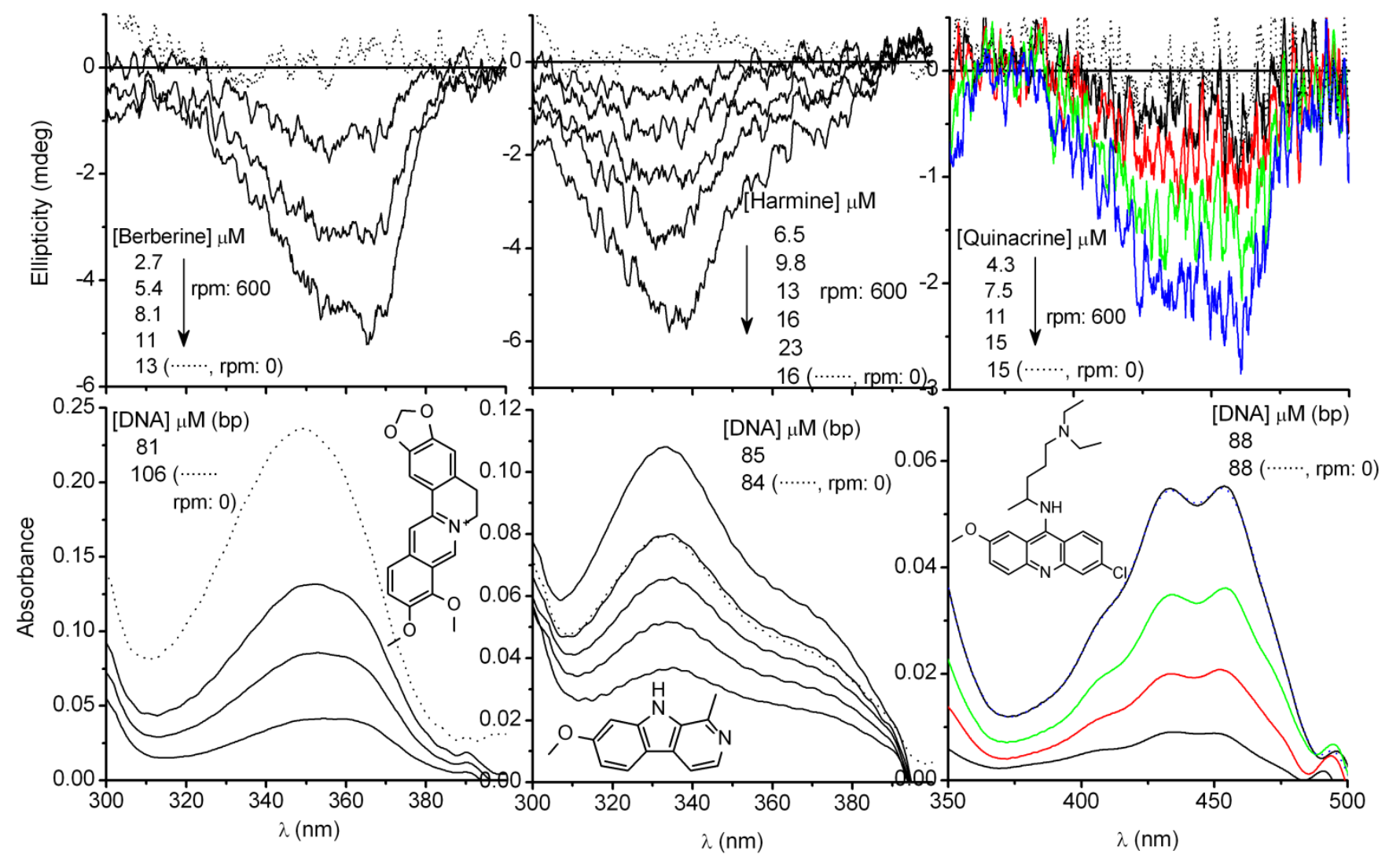

Figure 3

Comparison of $\mathrm{CD}$ and absorption spectra of drug-DNA complexes measured at $25^{\circ} \mathrm{C}$ in isotropic (dotted line, rpm: 0) and in stirred solution (solid lines, rpm: 600). For better distinction, CD curves of quinacrine are shown in colour. 

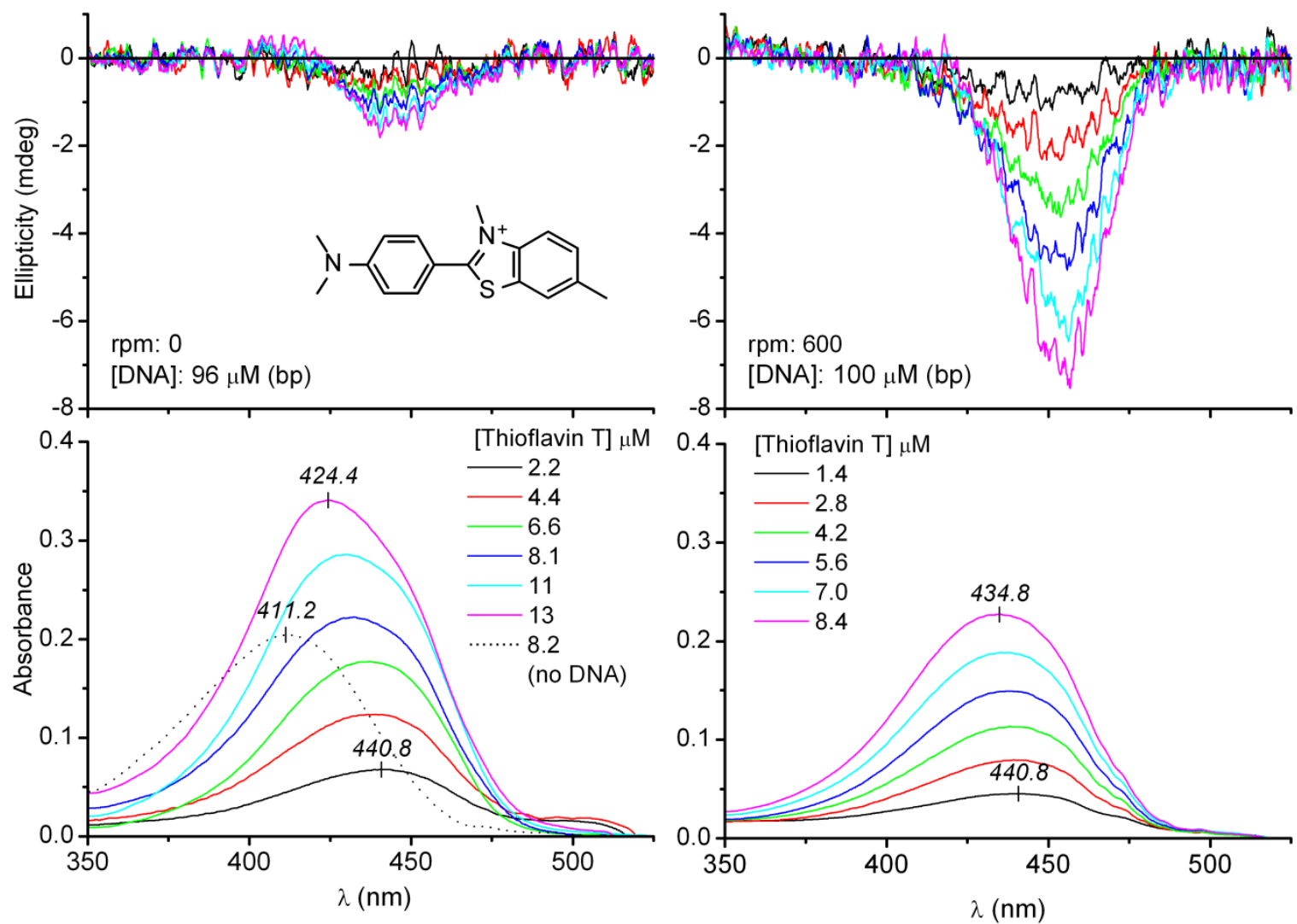

\section{Figure 4}

Comparison of $\mathrm{CD}$ and absorption spectra of thioflavin T-DNA complexes recorded in isotropic (left panels) and in stirred solution (right panels). Absorption band of the dye measured in DNA-free distilled water is shown (left panel, dotted line). 

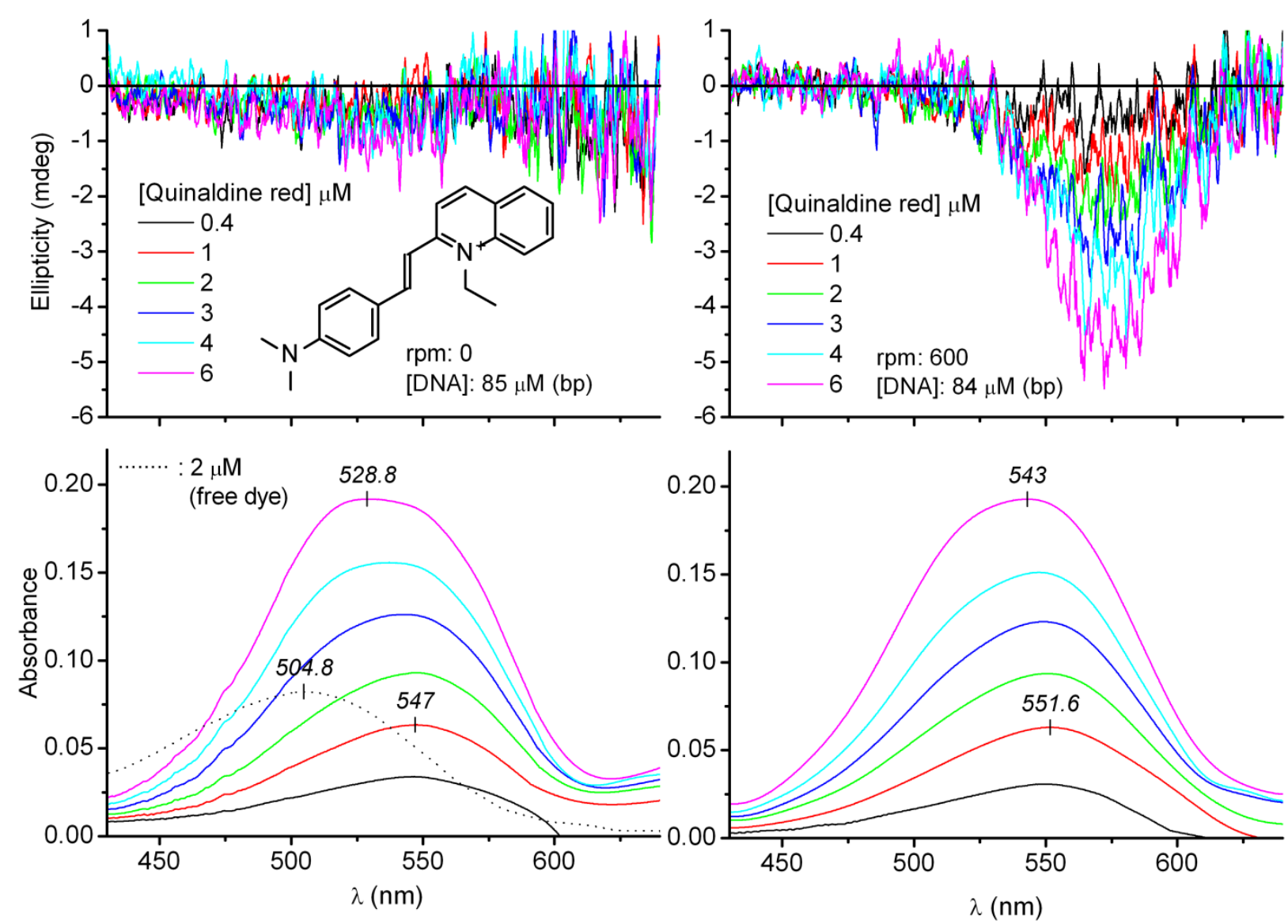

\section{Figure 5.}

Comparison of $\mathrm{CD}$ and absorption spectra of quinaldine red-DNA complexes measured at 25 ${ }^{\circ} \mathrm{C}$ in isotropic (rpm: 0) and in stirred solution (rpm: 600). Dotted line denotes the absorption curve of quinaldine red measured in DNA-free water. 

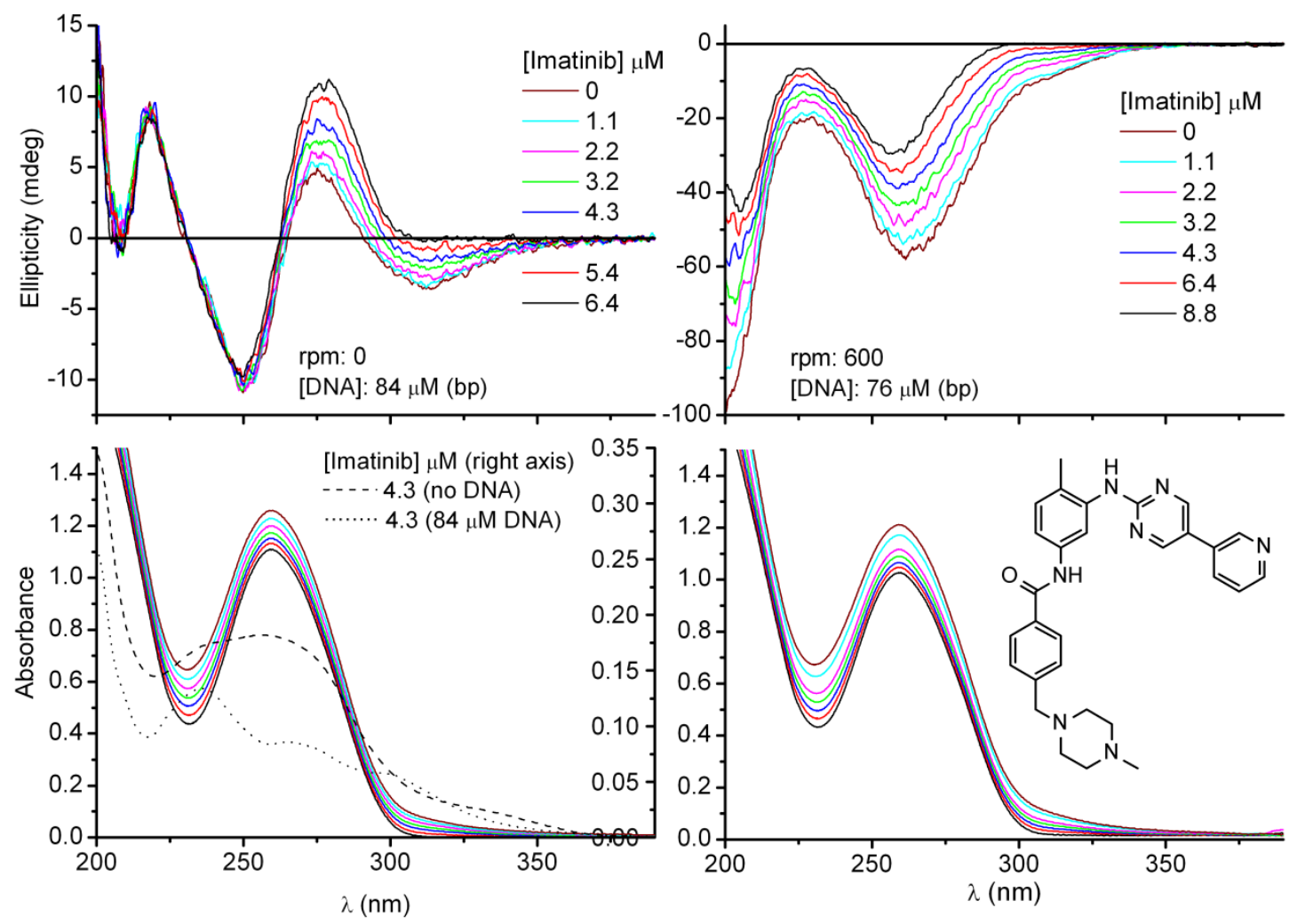

\section{Figure 6.}

Comparison of $\mathrm{CD}$ and absorption spectra of imatinib-DNA complexes measured at $25^{\circ} \mathrm{C}$ in isotropic (rpm: 0) and in stirred solution (rpm: 600). Dashed line: absorption curve of imatinib in DNA-free water. Dotted line: absorption spectrum of DNA-bound imatinib (UV contribution of DNA was subtracted). 
Supplementary Information 


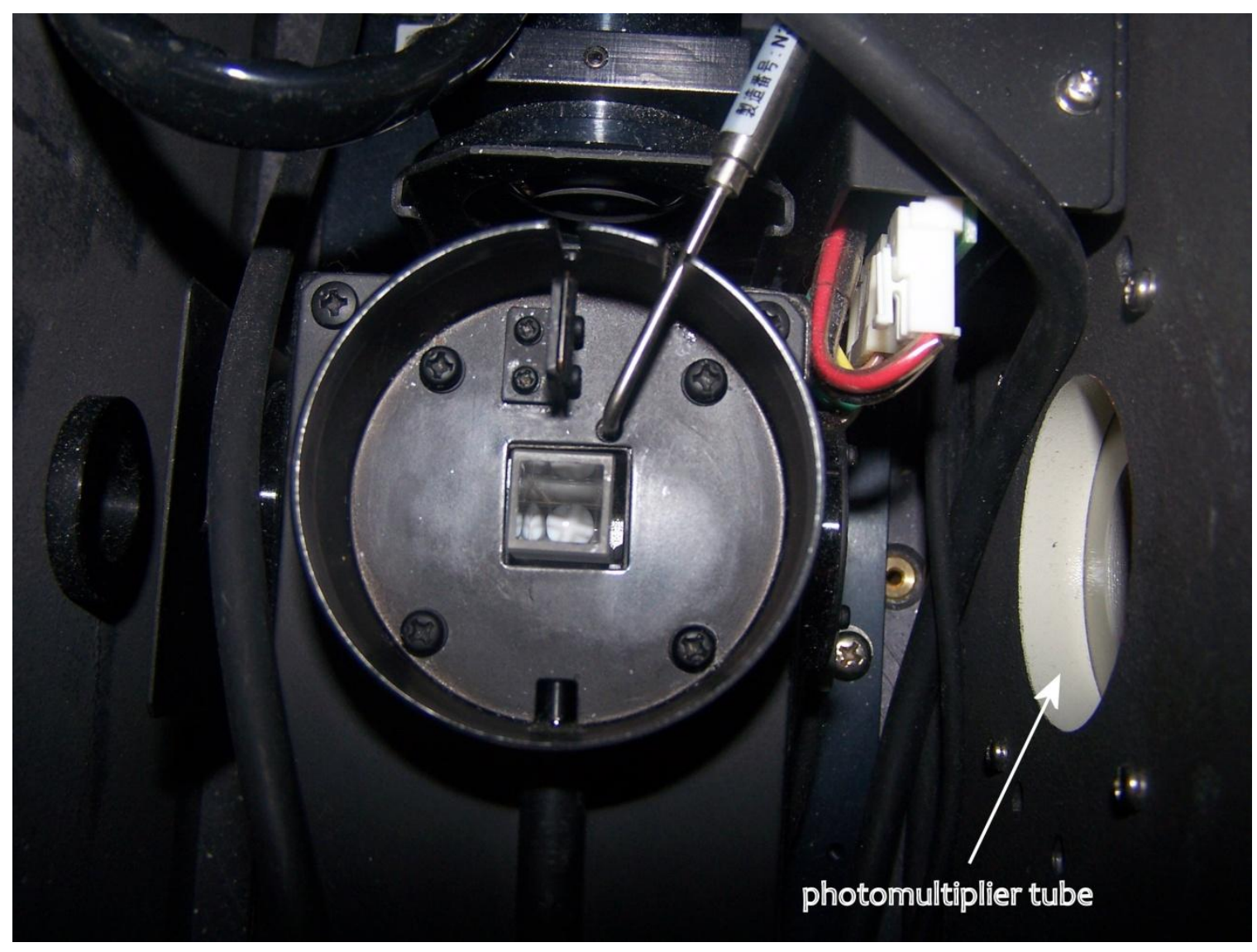

Supplementary Figure 1A.

Upper view of the internal unit of the JASCO PFD-350S Peltier thermostat mounted in the sample chamber of the JASCO J-715 spectropolarimeter. A $1 \mathrm{~cm}$ pathlength quartz cuvette (Hellma, USA) with a star head stirring bar is placed into the cuvette holder. 


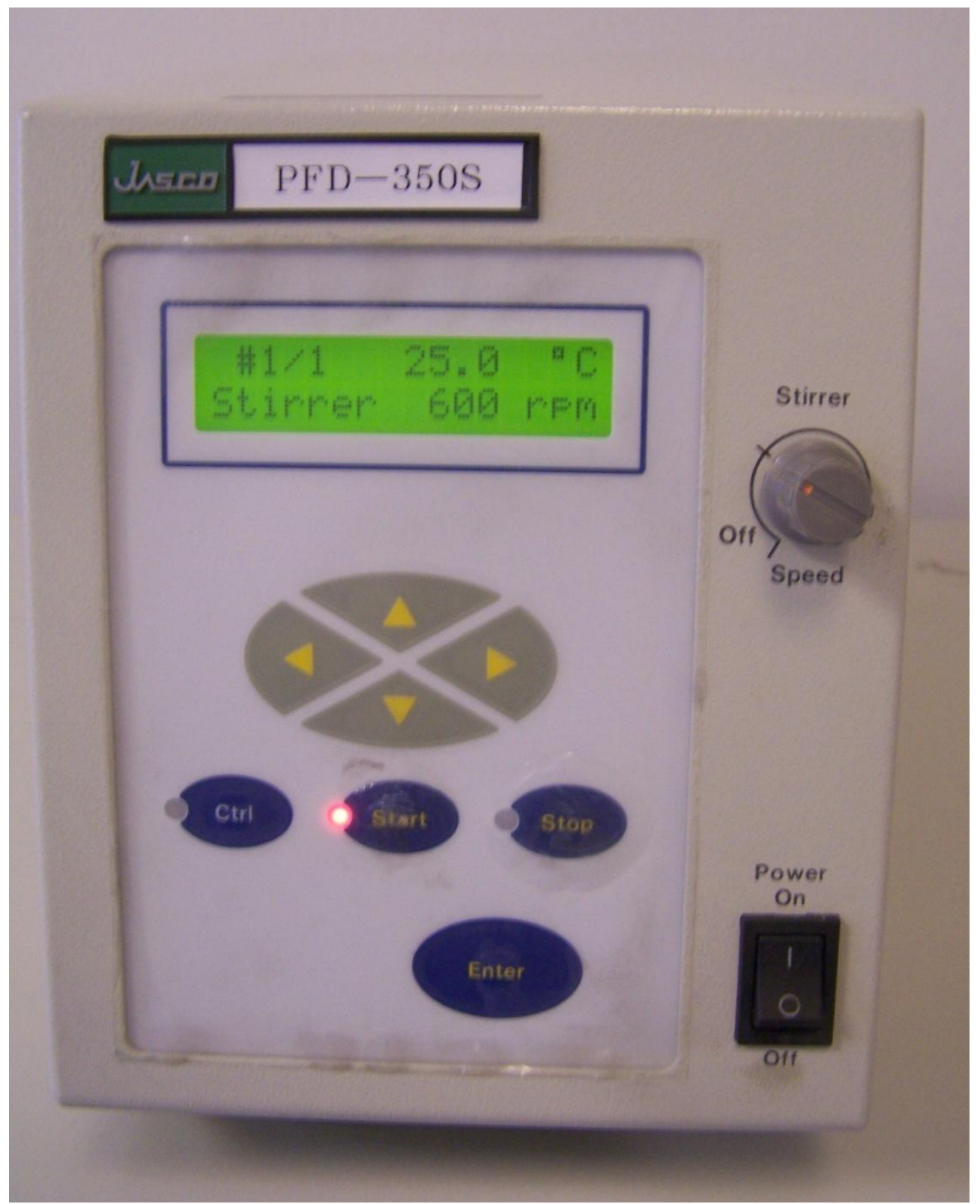

Supplementary Figure 1B.

Front view of the external controller unit of the JASCO PFD-350S Peltier thermostat. Stirring speed is set to $600 \mathrm{rpm}$. 


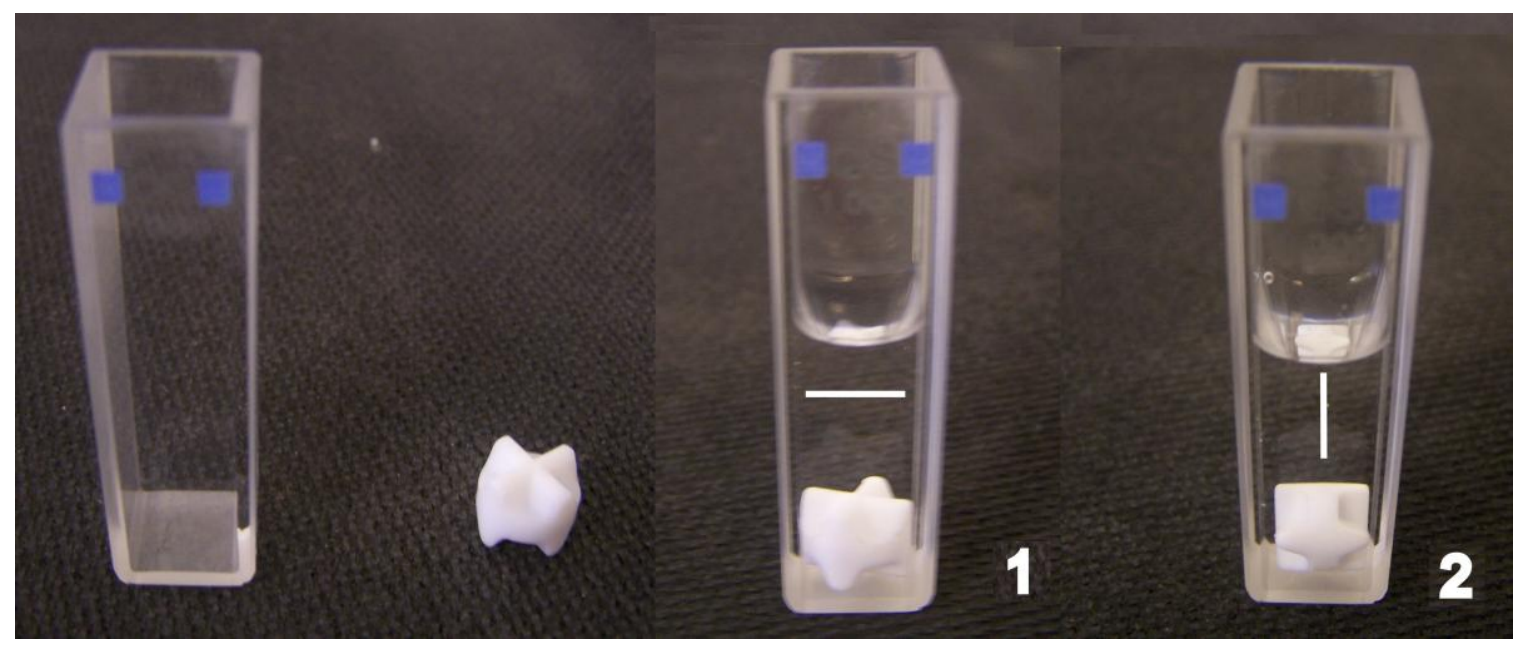

\section{Supplementary Figure 1C.}

Empty (left) and filled $(1,2)$ rectangular quartz cells of $1 \mathrm{~cm}$ optical pathlength $(1.8 \mathrm{~mL}$ DNA solution). White lines denote the proposed orientation of the long axis of DNA helices during rotation of the star head stirring bar. Except for the curve 'B' shown in Fig. 1B, all CD spectra were recorded by placing the stirring bar according to position $\mathbf{1}$. 


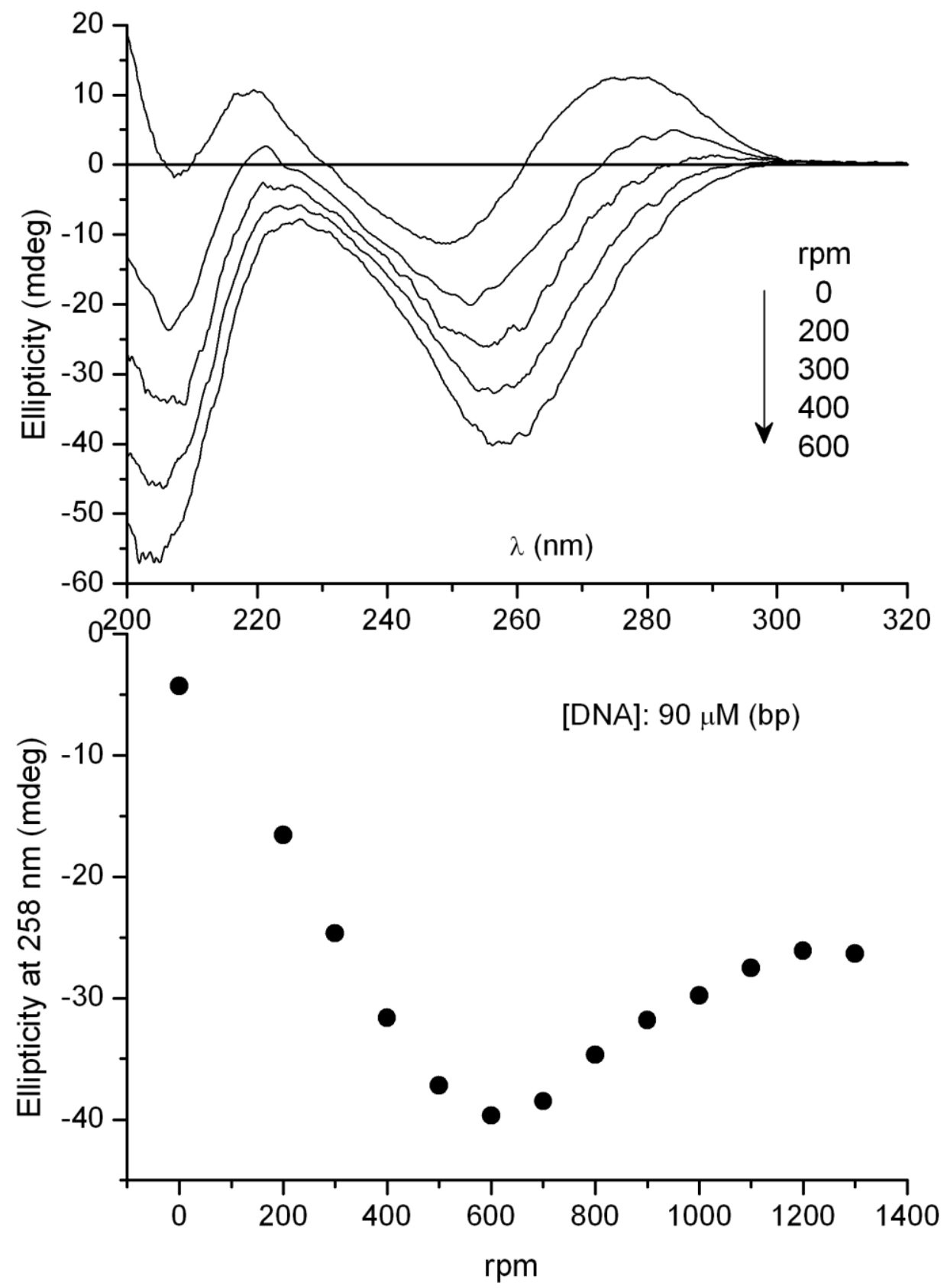

\section{Supplementary Figure 2.}

Top panel: rpm (revolutions per minute) dependence of the CD spectrum of DNA measured in aqueous solution $\left(25^{\circ} \mathrm{C}\right)$. Bottom panel: ellipticity values at $258 \mathrm{~nm}$ plotted against rpm. 


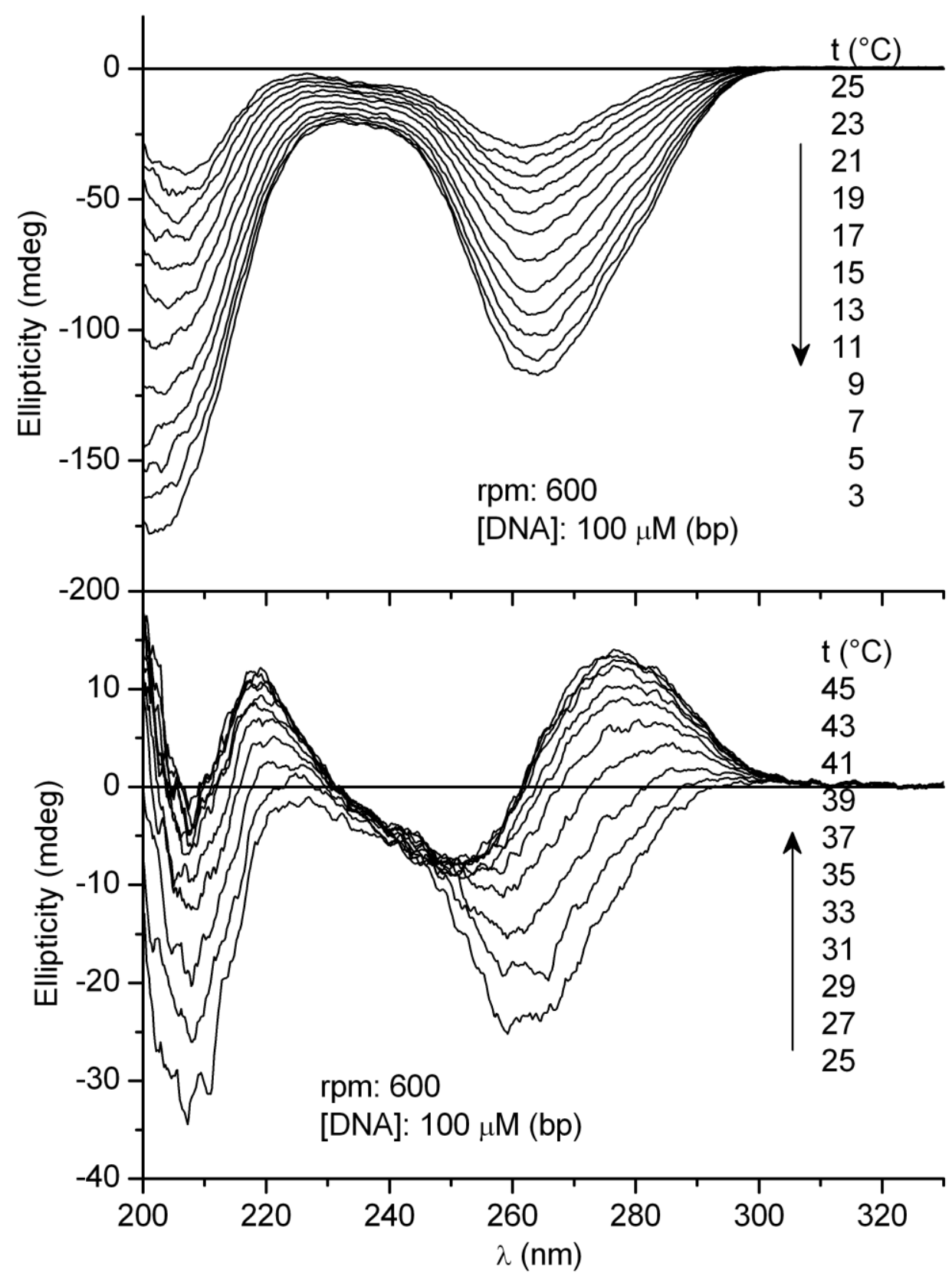

\section{Supplementary Figure 3.}

Top panel: CD spectra of $100 \mu \mathrm{M}$ DNA measured at decreasing temperatures (rpm: 600).

Bottom panel: CD spectra of $100 \mu \mathrm{M}$ DNA measured at increasing temperatures (rpm: 600). 


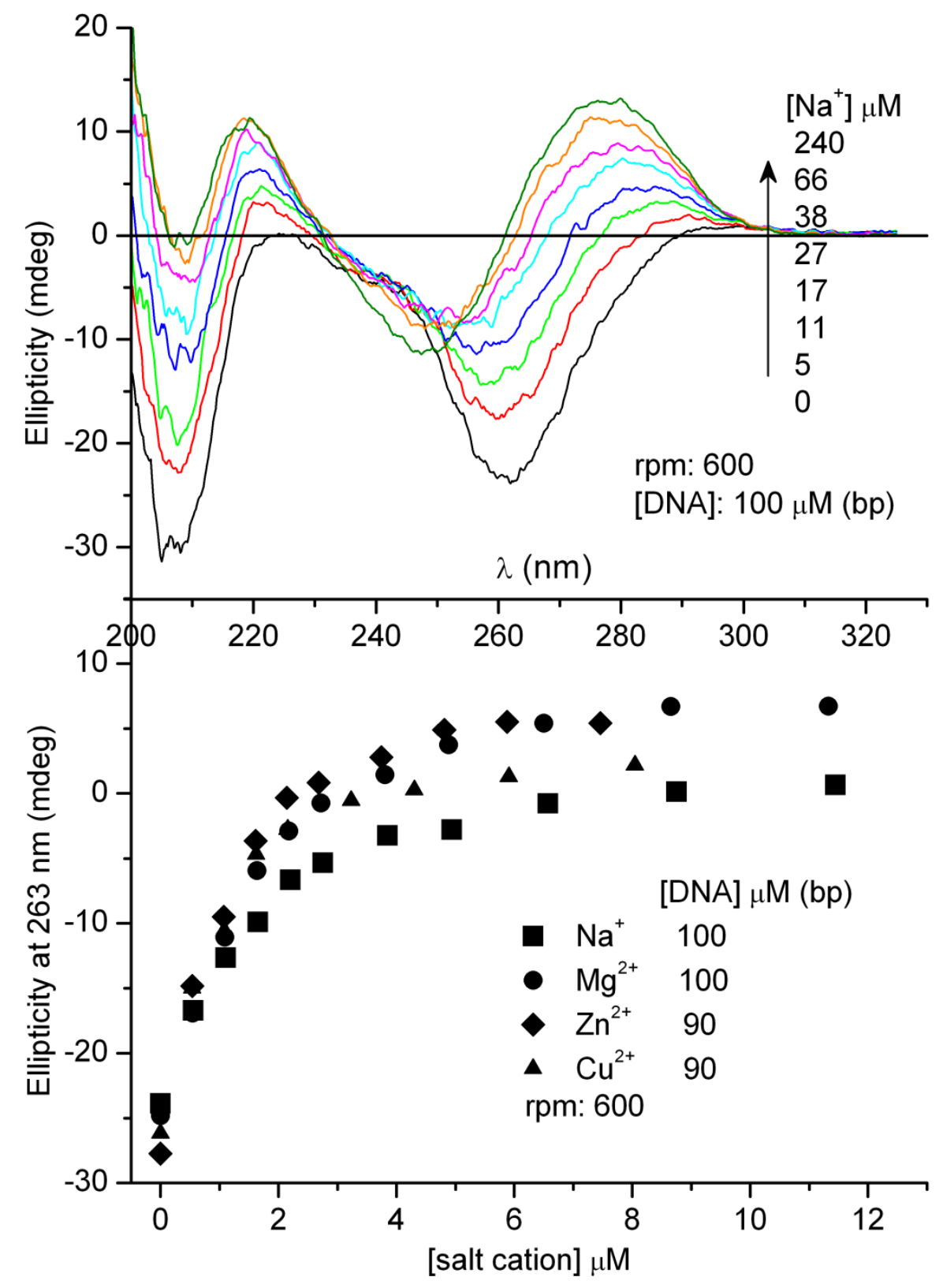

\section{Supplementary Figure 4.}

Top panel: CD spectra of DNA measured at increasing sodium ion concentrations. Bottom panel: ellipticity values plotted against increasing concentrations of various inorganic salts. 


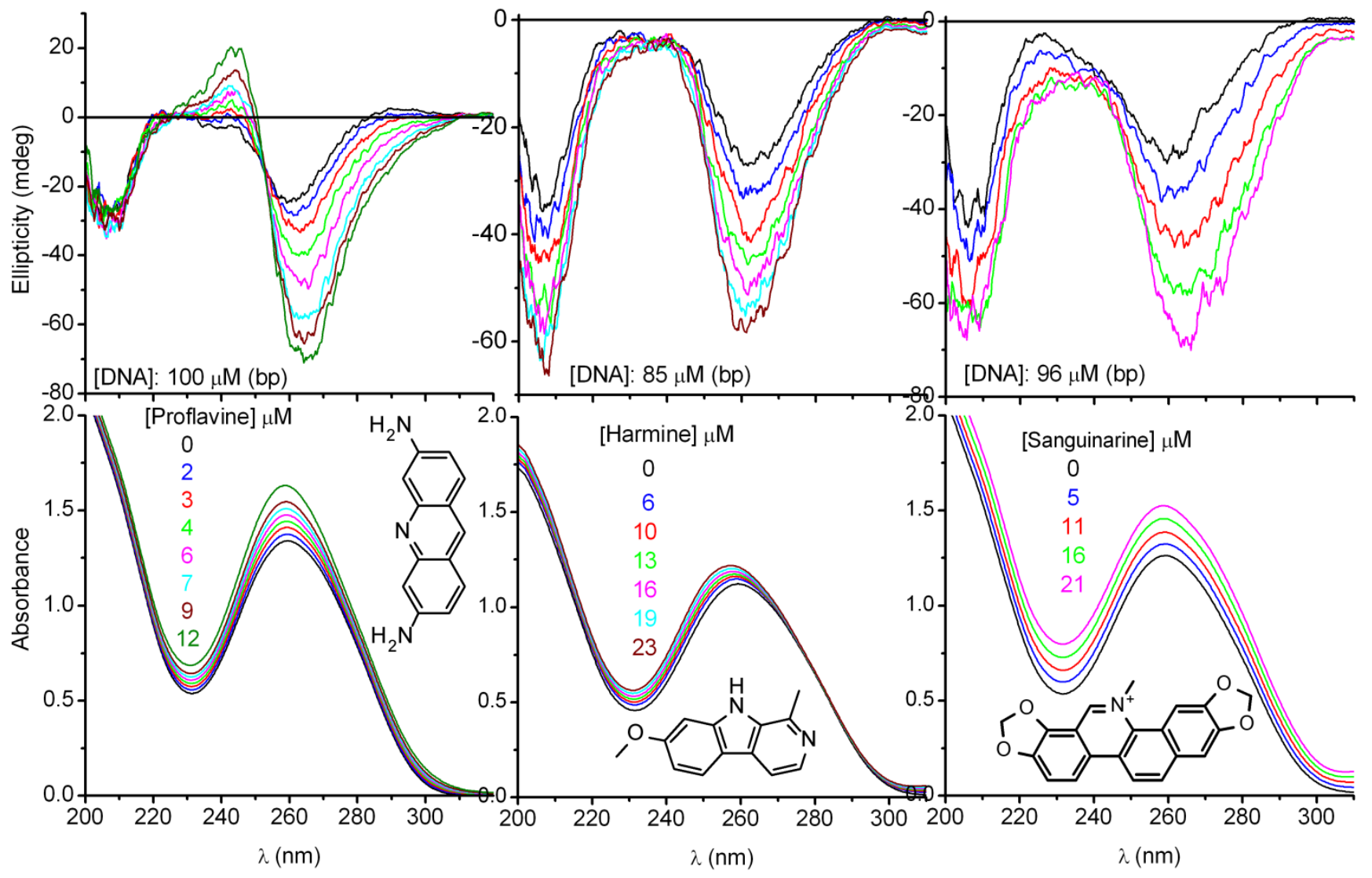

Supplementary Figure 5.

Changes of intrinsic CD and UV curves of stirring-oriented DNA upon addition of various intercalating agents (rpm: $600,25^{\circ} \mathrm{C}$ ). 


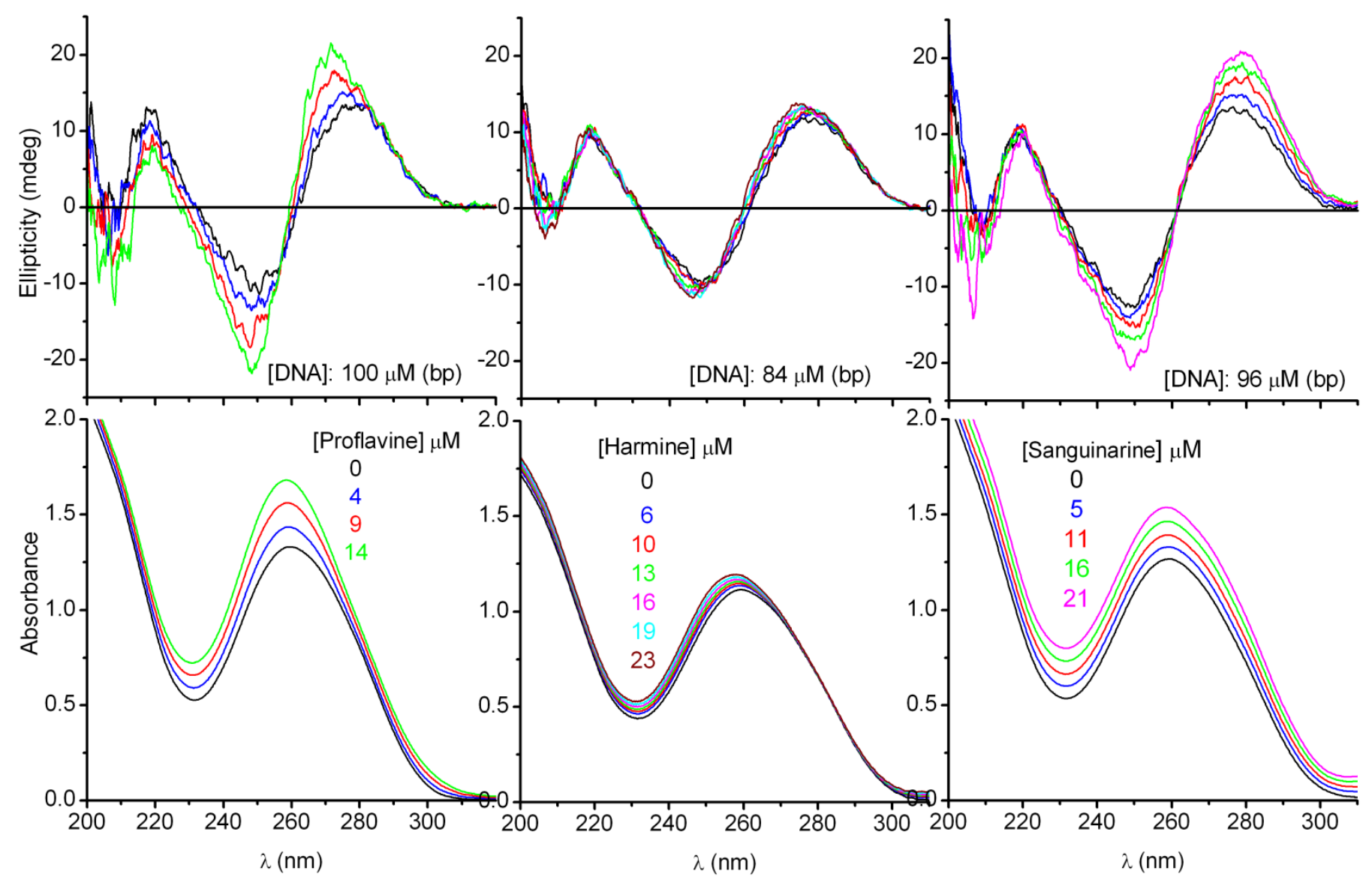

\section{Supplementary Figure 6.}

Intrinsic $\mathrm{CD}$ and UV curves of DNA measured under isotropic condition at increasing concentrations of various intercalating agents (rpm: $0,25^{\circ} \mathrm{C}$ ). 

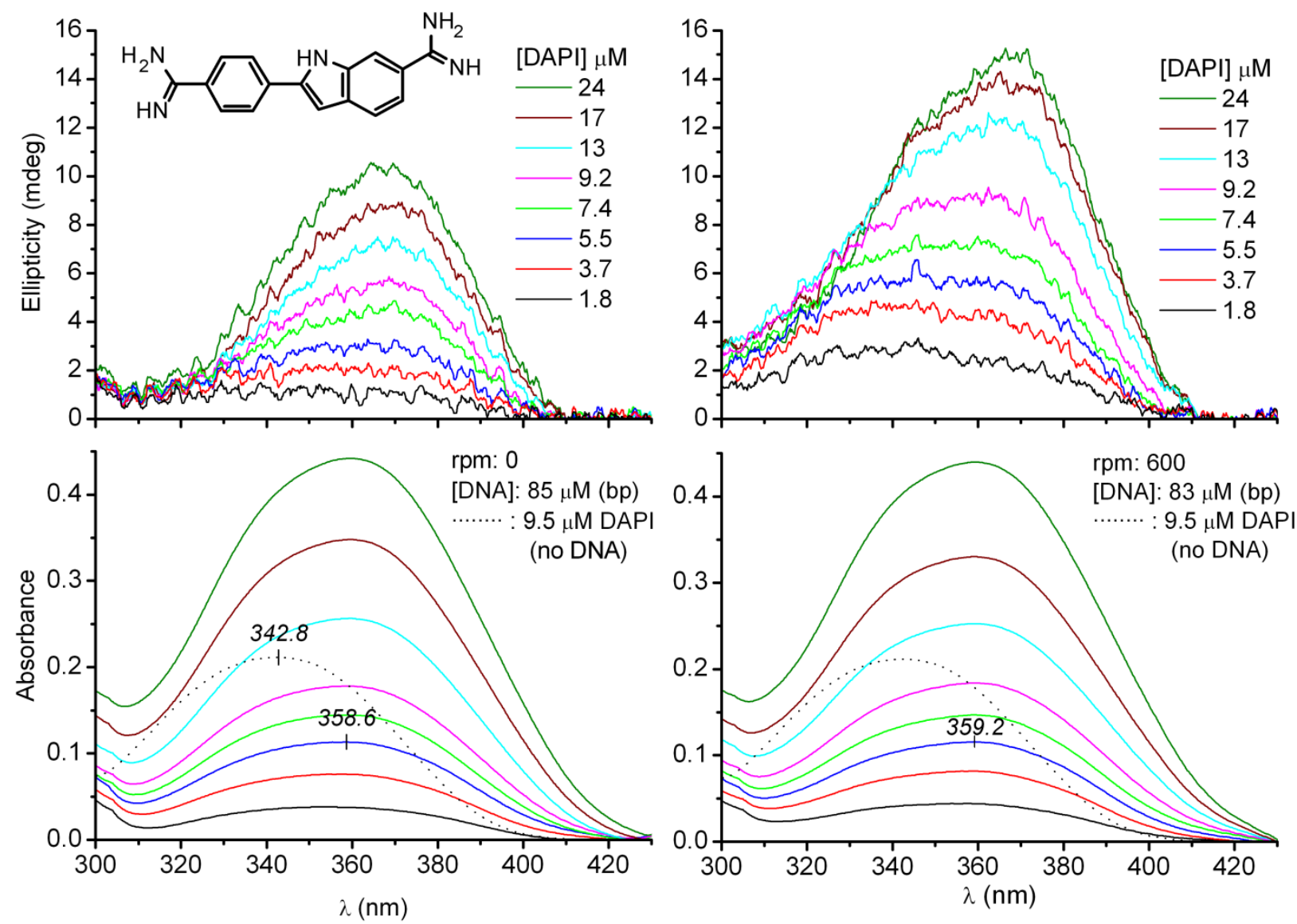

\section{Supplementary Figure 7.}

Comparison of CD and absorption spectra of DAPI-DNA complexes measured at $25^{\circ} \mathrm{C}$ in isotropic (rpm: 0) and in stirred solution (rpm: 600). Dotted line denotes the absorption curve of DAPI measured in DNA-free water. 

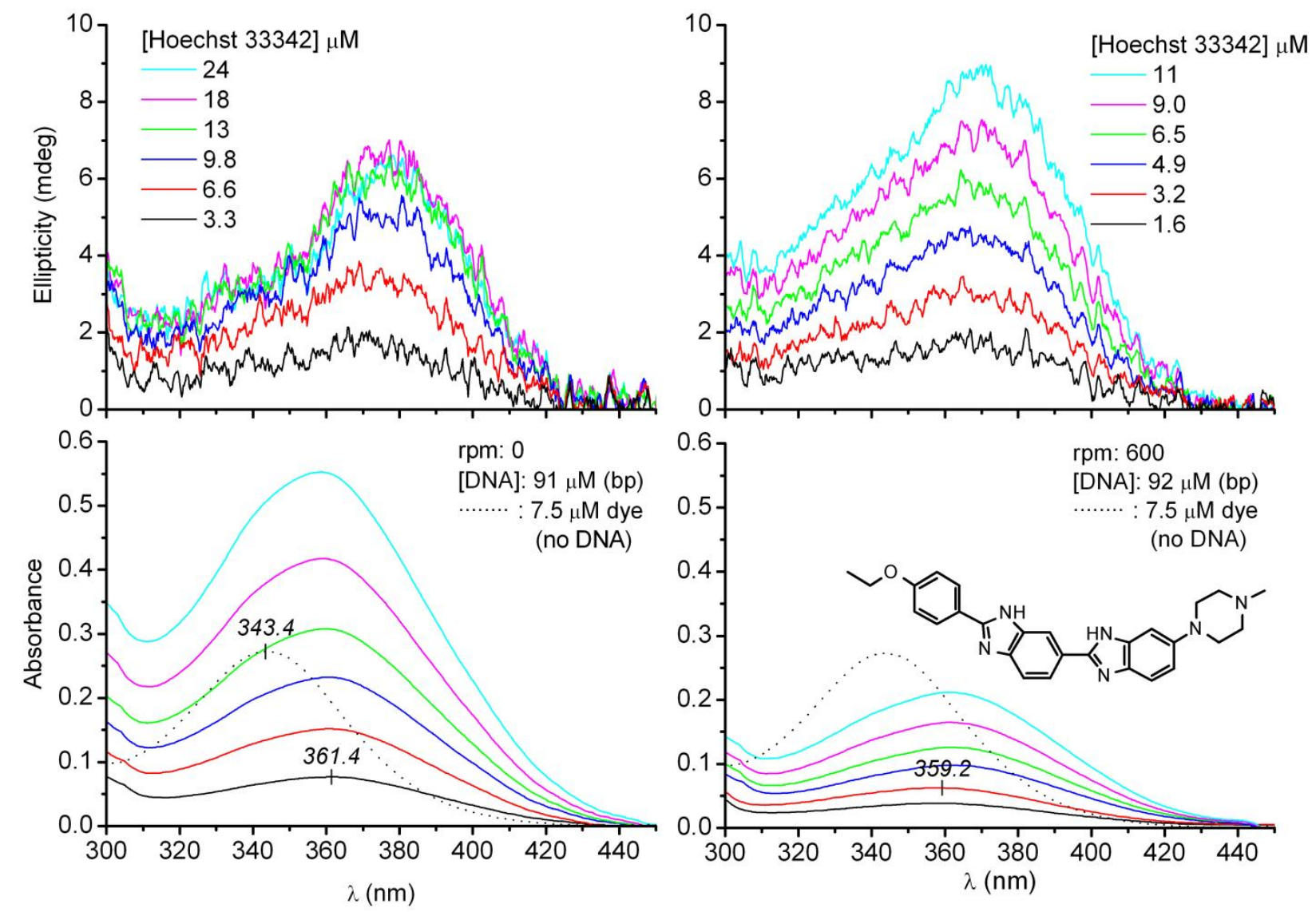

\section{Supplementary Figure 8.}

Comparison of CD and absorption spectra of Hoechst 33342-DNA complexes measured at 25

${ }^{\circ} \mathrm{C}$ in isotropic (rpm: 0) and in stirred solution (rpm: 600). Dotted line denotes the absorption curve of Hoechst 33342 measured in DNA-free water. 


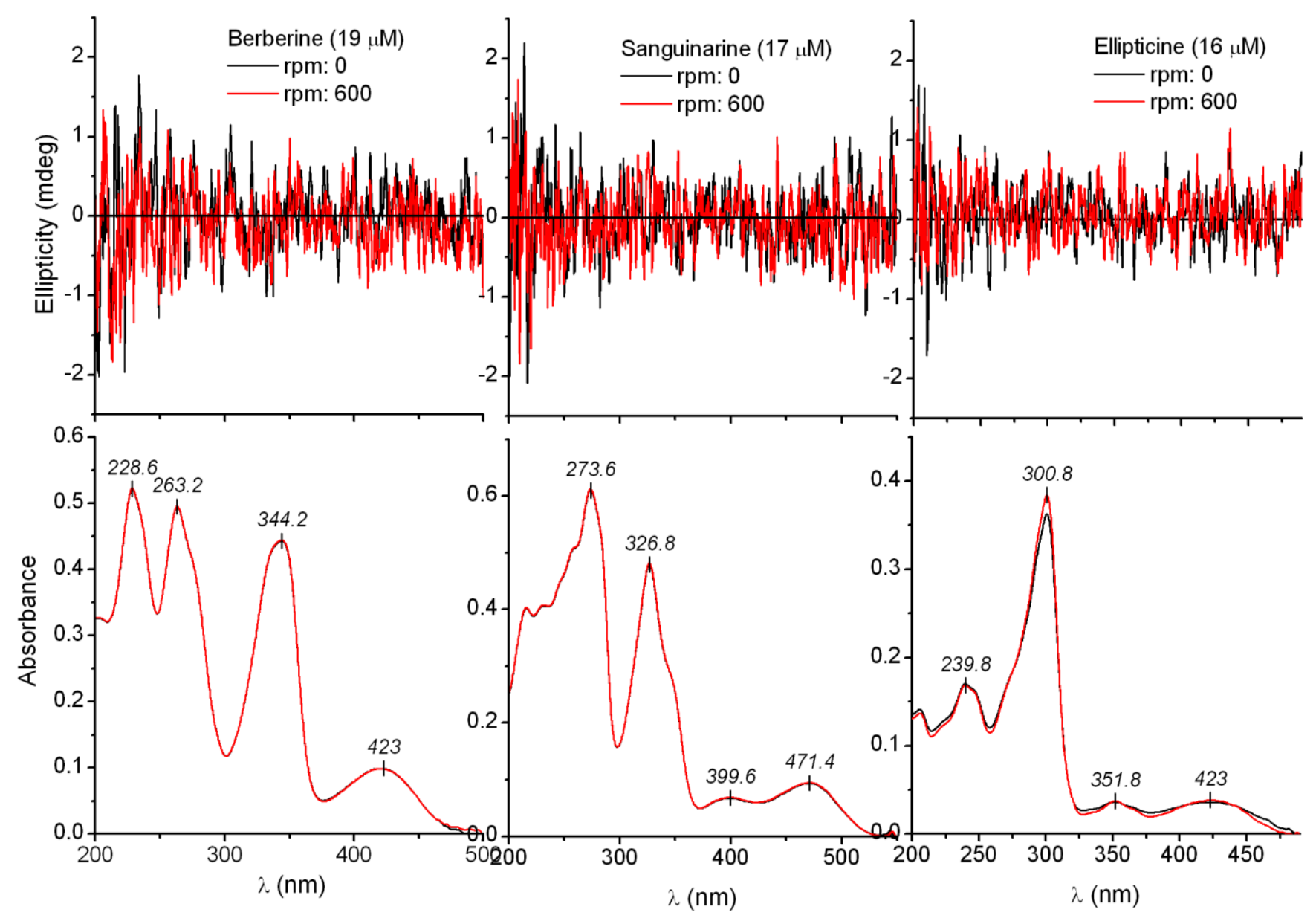

Supplementary Figure 9A.

$\mathrm{CD}$ and absorption spectra of berberine, sanguinarine, and ellipticine measured at $25^{\circ} \mathrm{C}$ in stirred (rpm: 600) and non-stirred aqueous solutions (rpm: 0). 


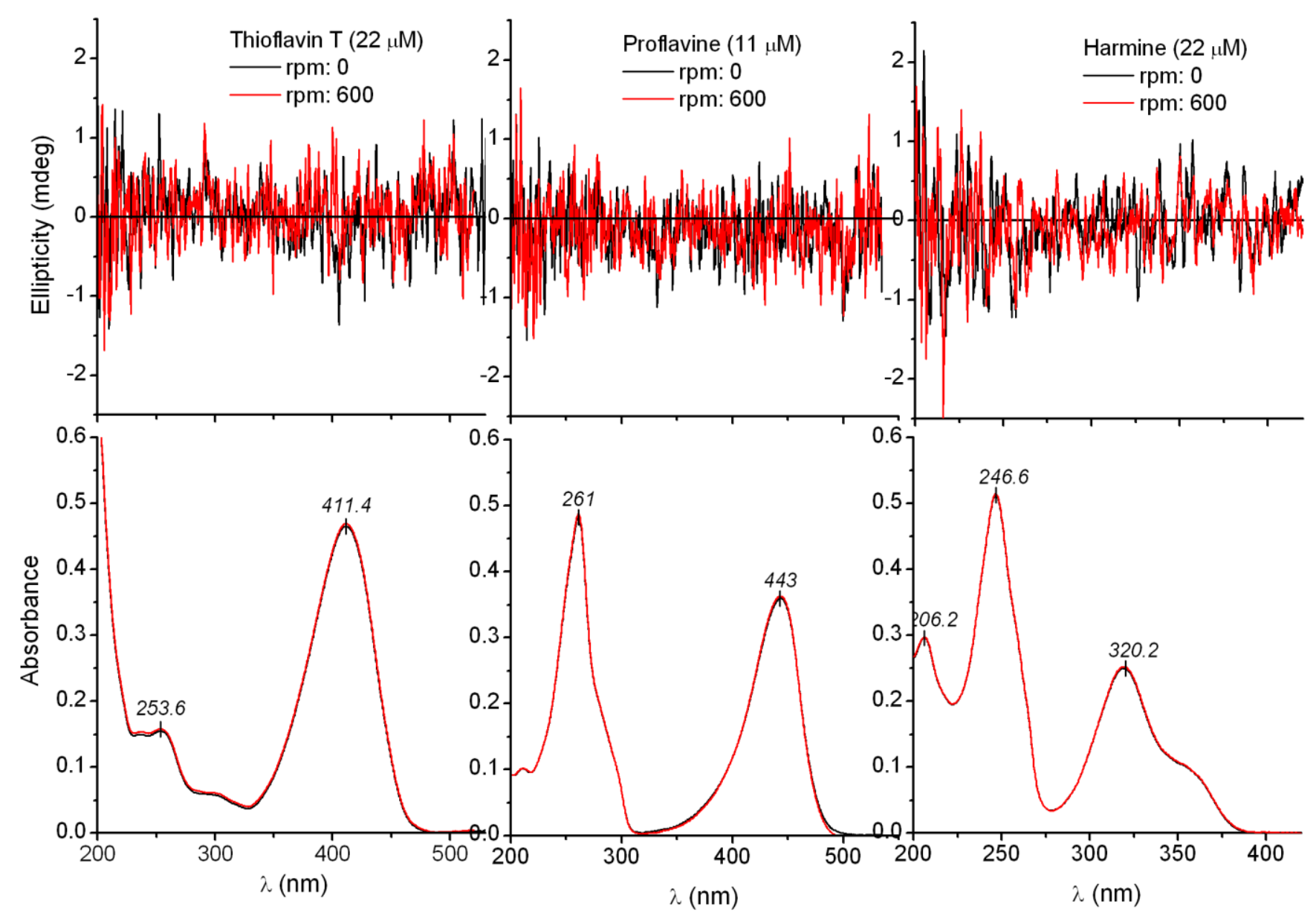

Supplementary Figure 9B.

$\mathrm{CD}$ and absorption spectra of thioflavin $\mathrm{T}$, proflavine, and harmine measured at $25{ }^{\circ} \mathrm{C}$ in stirred (rpm: 600) and non-stirred aqueous solutions (rpm: 0). 


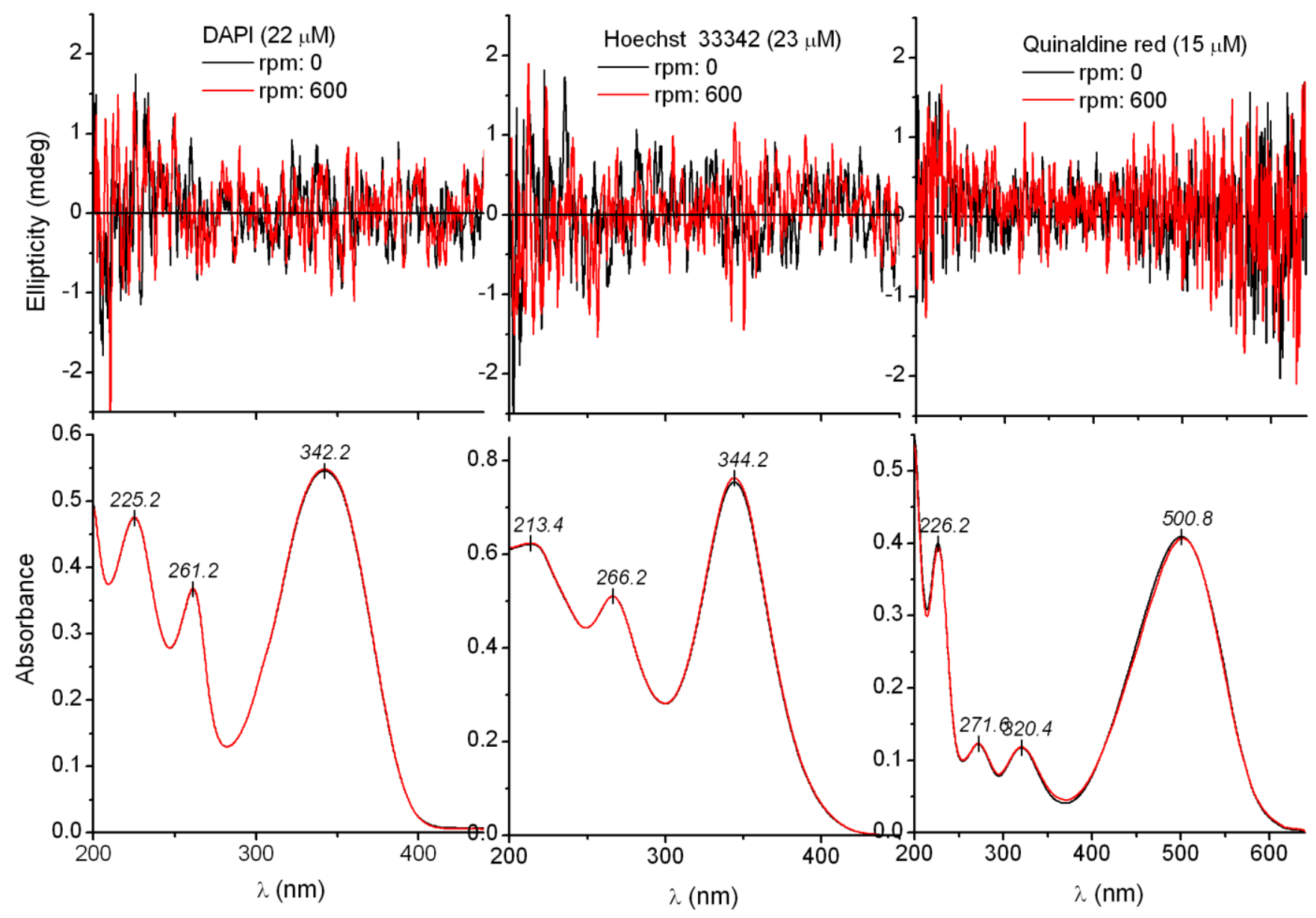

Supplementary Figure 9C.

$\mathrm{CD}$ and absorption spectra of DAPI, Hoechst 33342 , and quinaldine red measured at $25^{\circ} \mathrm{C}$ in stirred (rpm: 600) and non-stirred aqueous solutions (rpm: 0). 


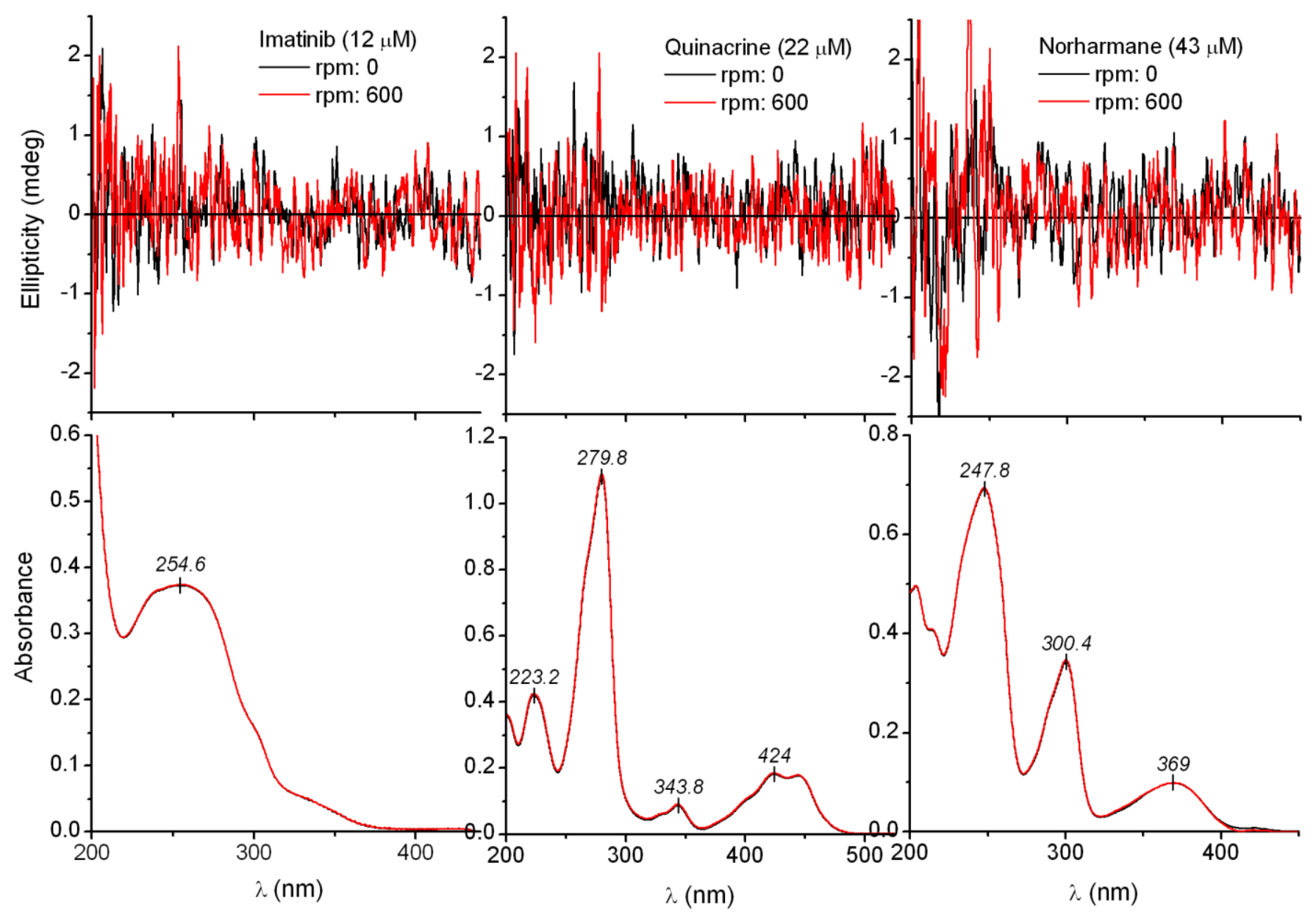

Supplementary Figure 9D.

$\mathrm{CD}$ and absorption spectra of imatinib, quinacrine, and norharmane measured at $25{ }^{\circ} \mathrm{C}$ in stirred (rpm: 600) and non-stirred aqueous solutions (rpm: 0). 